\title{
Design Database for an Automated Control System of Typical Wastewater Treatment Processes
}

\author{
Anatolii I. Zhuchenko ${ }^{a}$, Liudmyla V. Osipa ${ }^{b}$, Evgeniy S. Cheropkin ${ }^{c}$ \\ ${ }^{a, c}$ Department of Chemical Production Automation, National Technical University of Ukraine "Igor Sikorsky \\ Kyiv Polytechnic Institute”, Kyiv, Ukraine \\ ${ }^{b}$ Department of Electronic and Computer Engineering, National Transport University, Kyiv, Ukraine
}

\begin{abstract}
Current requests, that are advanced to the cleaning parameters of wastewaters, including the offered by the EU community standards, are quite high. To satisfy them, a lot of parameters need to be maintained at a proper level. The presence of a significant number of control points, and a wastewater treatment process management, many situations affect the cleaning process in the case of deviations from the specified conditions, as well as many pollutants indicate that currently structured information for quality cleaning processes management should be available. Even an experienced operator cannot handle the monitoring and management of so many parameters optimally without the relevant database. The modern phase of the water-saving technology enterprises is characterized by large volumes and complexity of the information being processed, by the need for public access to data elements, by high demands to the speed of the information acquisition and its reliability that can be realized under the conditions of the functioning database.

Since the database should not only be a storage, but should also have a link between the different elements, the data structure must be described formally. For that reason, the database subschema was designed (as the conceptual data model) for automation of water-saving processes. With the help of normalization, the hierarchical database model has been reduced to relational. It has significant advantages over the hierarchical and network data structures including the following: clarity of data presentation, ability to use one relational algebra (a language of Codd algebra), as well as simplicity of database reorganization. Due to the lack of a recognized analytical method of database management system selection, the choice of database for automatic water-saving control processes was carried out based on an expert estimations method. To maintain the functioning of the database on the defined criteria, the PostgreSQL database management system has been selected. As a result, that will implement the interface with application software concerning the automation of wastewater treatment technological processes, as well as the main production automation.
\end{abstract}

Index Terms: Wastewater, automated control system (ACS) of typical wastewater treatment processes, database of ACS of typical wastewater treatment processes, database schema, database subschema of ACS of typical wastewater treatment processes, client-server database architecture, database management system PostgreSQL.

\footnotetext{
* Corresponding author.

E-mail address: zhaniv@ukr.net.
} 


\section{Introduction}

Nowadays enterprises having wastewater in their work cycle pay a significant attention to water supply. This is due to the large fines that can be imposed on them and with the humanitarian attitude to the environment. In respect to the reservoir as a great capacity to dilute polluted water, this action will reduce its quality and cause the death of water micro flora [1]. Sewage discharge into water bodies lead to the changes of biological and environmental conditions.

The need for automated control systems of wastewater purification processes is caused by a nonstationary and the need to use many blocks (sometimes over 100) to implement effective purification.

To control the water supply process effectively it is necessary to have an appropriate data based on the main technological purification parameters. They are provided in regulatory document of environmental issues. The quality of cleaning depends also on the trustworthiness of the information about the principal enterprise operation and the composition of waste water [2]. To meet the high standard requirements, it is necessary to maintain a lot of parameters at the proper level. There are a lot of factors indicating that for effective managing of purification processes it is necessary to have current structural data. They are represented with the following: presence of safety points and wastewater purification managing process, many situations which influence on the purification processes in case of deviation from the specified conditions and a lot of pollutants. Even for an experienced operator it is challenging to monitor and control a significant number of parameters optimally without a database.

Introduction of automated control systems that operate using the database provide additional opportunities in the implementation of quality control. We can therefore say that effective wastewater treatment is impossible without a database.

\section{Statement of the Problem}

The case study of developing an automated control systems database of wastewater purification processes $[3,4,5,6]$ makes it possible to conclude that the current low-technology enterprises solve the problem by using local data, which does not allow collective data access and the time necessary to get reliable information. In condition of process control wastewater, it leads to pollution and environmental damage. Therefore, the development of automated control system for typical wastewater treatment processes an important question of database development thus allowing to obtain reliable information for management tasks of almost any complexity.

If the early stages of implementation of automated control system of wastewater purification were resolved, the problem of handling of small amounts of information organization and data access is completely determined by the specific software systems [7]. The current phase of low-technology enterprises is characterized by high volumes and complexity structures processed information, the need for public access to data elements, demanding to speed up retrieval and the reliability that can be achieved in terms of the database operation.

If the purpose of the database was only to store data, its structure would be simple. The reason for its complexity is determined by connections between different data elements. Thus, the data structure should be described in a formal way. Description of the logical data structure is used by software database management system (DBMS) when processing user requests (or applications) for information. That is why the first task in the databases development is to develop a conceptual model data (overall logical structure of the database schema or subschema DB). In the future, it is necessary to select a database to sustain database.

Due to the analysis of the literature adequate attention to such issues as a formalized data description and the 
physical implementation of a database for managing of typical wastewater treatment processes is not paid.

\section{Subschema Database of an ACS of Typical Wastewater Treatment Processes}

The aim is to develop a logical description database for the automated control system of typical wastewater treatment processes, receiving data structures relational database model, presentation approaches when choosing database management systems and making choices DBMS.

Development of a database for managing typical wastewater treatment processes performed based on computer database organization methodology $[8,9,10]$. According to this methodology, the term schema is used to define a complete table of all types of data elements and types of records that are stored in the database. The term subschema means data description which is used for a set of specific tasks.

In developing logical description database of ACS of typical wastewater treatment processes needed data set for control was identified. Data presented at the logical level user reflect its view of the database at solving specific problems. The introduction of such data representation level significantly reduces the processing of requests, increases the database safety and expands the scope of their use.

Database schema for the automated control system of wastewater emissions includes two structures which look like a tree structures (Figure 1).

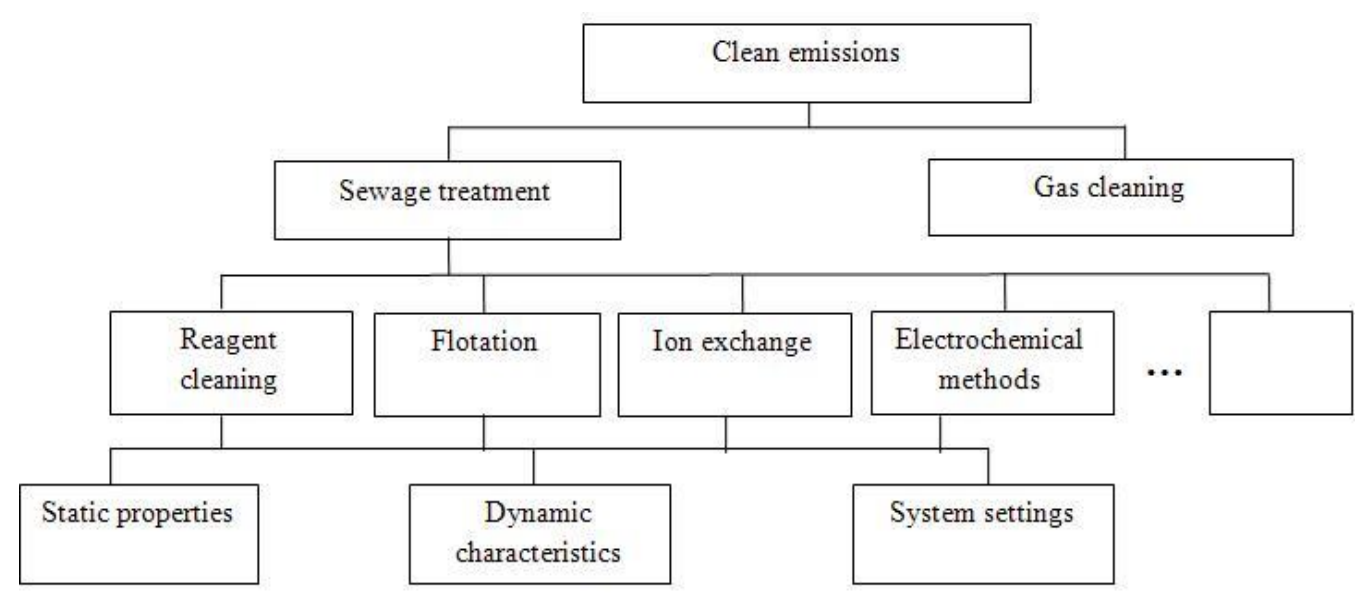

Fig.1. The Hierarchical Model Database of ACS of Purification Processes Harmful Emissions.

The root of each tree that is on the top level of the hierarchy is a record that includes the name and code of cleaning (or wastewater cleaning or purification gas emissions). The following hierarchy level which is subordinated to the first has records that show the methods of cleaning and their codes. The lower level of the hierarchy is formed by records for management tasks on certain methods of cleaning.

The minimum accessible unit of information in a hierarchical model is the node that is one line in each level. Search-based hierarchical data model is made from top to bottom and from left to right. Therefore, to find any mode, you need to identify the node that is searched and those components to which it is subordinate. That is a disadvantage of the hierarchical database. Besides, it is difficult to conduct editing, insertion and removing of all subordinate levels, what also complicates the database operation. Submission of data in a tree will stop the development and a significant increase in the database. At a certain stage of its growth there can be a potential violation of logical view; this would entail the need for changes in applications. As a result, one of the main advantages of the database i.e. independence of the data can be removed. This disadvantage is eliminated in a relational database in which data is presented in the form of two-dimensional tables. This is one of the most 
natural ways of presenting data to a user. Since any lattice structure can be expanded with some redundancy in the set of tree structures, also redundancy and hierarchical data representation may be reduced to twodimensional flat files. Links between data which are shown in Figure 2 are presented in the form of twodimensional tables. This was done for each connection between the data by taking normalization step by step [10]. Tables are constructed in a way connection between data elements are not lost.

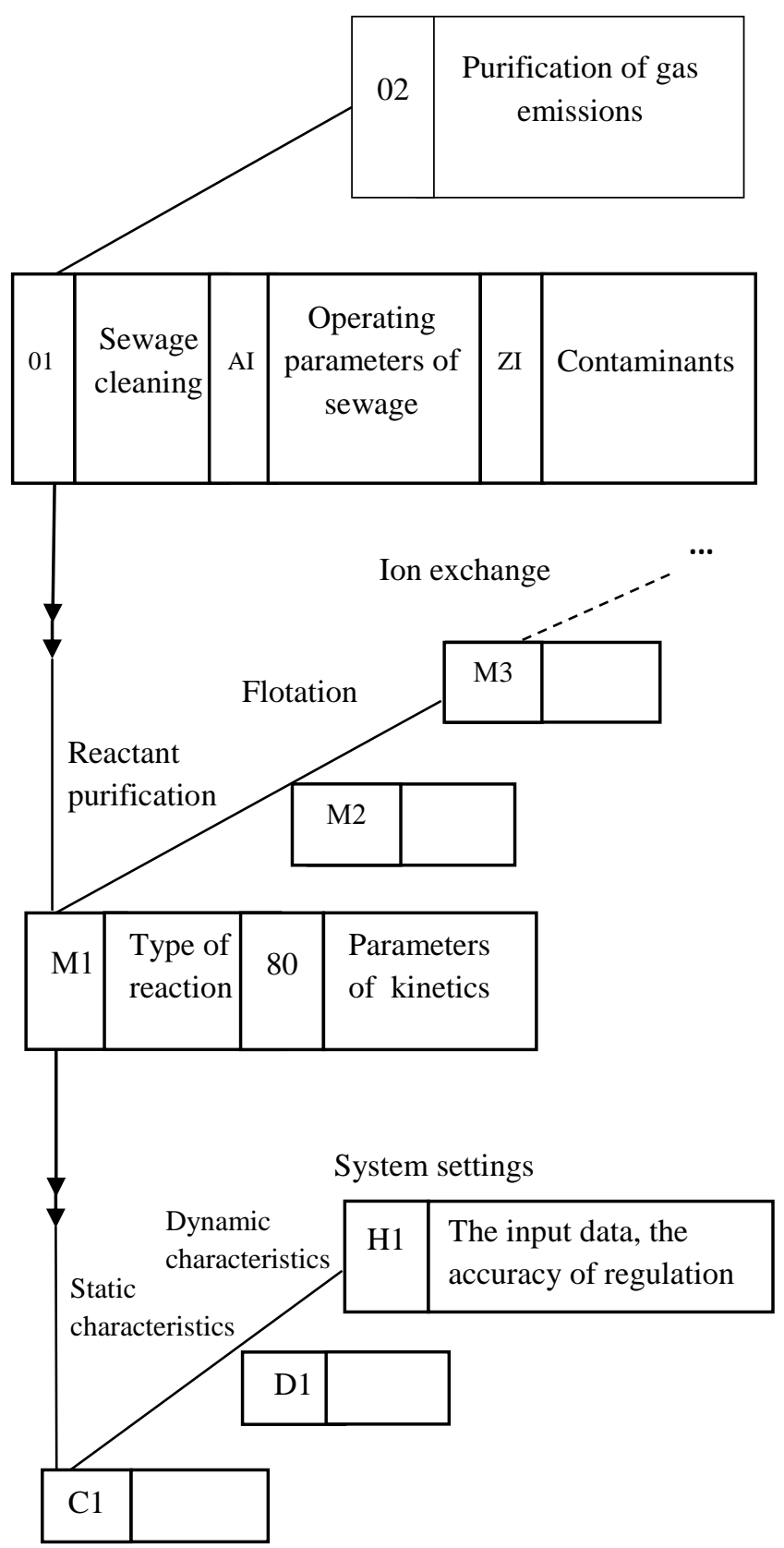

Fig.2. Database Subschema of ACS of Typical Wastewater Treatment Processes 
Lacking for support static links relational connections of database management systems are different. They are connected by set only for solving a problem and exist only for the period of its solution. So, when hierarchical model is displayed on relational one, all the structural relationships are not described explicitly, but are only checked for the possibility of establishing these relations. Obligatory condition of communication between the relational respect is the presence of at least one common attribute that is the key to performing communication (for further search data) $[11,12,13]$.

The normalized form of subschema database takes the following form: the initial relation: SEWAGE STRUCTURE (type code of cleaning, the code of operelationnal parameters of wastewater, pollutants code) table 1.

Table 1. Composition of Wastewater

\begin{tabular}{|c|c|c|c|c|c|}
\hline $\begin{array}{l}\text { Code of } \\
\text { cleaning } \\
\text { type }\end{array}$ & $\begin{array}{l}\text { Type of } \\
\text { cleaning }\end{array}$ & $\begin{array}{c}\text { Code of } \\
\text { operelationnal } \\
\text { parameters of } \\
\text { wastewater }\end{array}$ & $\begin{array}{c}\text { Operelationn } \\
\text { modes means } \\
\text { settings }\end{array}$ & $\begin{array}{c}\text { Code } \\
\text { pollutants }\end{array}$ & Type of pollution \\
\hline 1 & 2 & 3 & 4 & 5 & 6 \\
\hline 01 & $\begin{array}{l}\text { Wastewater } \\
\text { cleaning }\end{array}$ & A1 & $\begin{array}{c}\text { The range of } \\
\text { concentrelationns } \\
\text { of pollutants }\end{array}$ & $\mathrm{Z1}$ & $\begin{array}{l}\text { Strong acids and } \\
\text { alkalis }\end{array}$ \\
\hline 01 & $\begin{array}{l}\text { Wastewater } \\
\text { cleaning }\end{array}$ & A1 & $\begin{array}{c}\text { The range of } \\
\text { concentrelationns } \\
\text { of pollutants }\end{array}$ & $\mathrm{Z} 2$ & $\begin{array}{l}\text { Mixture of strong } \\
\text { and weak acids }\end{array}$ \\
\hline 01 & $\begin{array}{l}\text { Wastewater } \\
\text { cleaning }\end{array}$ & A1 & $\begin{array}{l}\text { The range of } \\
\text { concentrelationns } \\
\text { of pollutants }\end{array}$ & $\mathrm{Z} 3$ & $\begin{array}{l}\text { Strong acids and } \\
\text { heavy metalions }\end{array}$ \\
\hline 01 & $\begin{array}{l}\text { Wastewater } \\
\text { cleaning }\end{array}$ & A1 & $\begin{array}{l}\text { The range of } \\
\text { concentrelationns } \\
\text { of pollutants }\end{array}$ & $\mathrm{Z} 4$ & $\begin{array}{l}\text { Cyanide and hexa- } \\
\text { valent chromium }\end{array}$ \\
\hline 01 & $\begin{array}{l}\text { Wastewater } \\
\text { cleaning }\end{array}$ & A1 & $\begin{array}{l}\text { The range of } \\
\text { concentrelationns } \\
\text { of pollutants }\end{array}$ & $\mathrm{Z} 5$ & $\begin{array}{l}\text { Organic substances } \\
\text { and suspended } \\
\text { material }\end{array}$ \\
\hline$\ldots$ & $\ldots$ & $\ldots$ & $\ldots$ & $\ldots$ & $\ldots$ \\
\hline
\end{tabular}

Induced relation: METHODS OF CLEANING AND TYPES OF REACTIONS (code of type cleaning, code cleaning method, the code type of reaction kinetics parameters, operation parameters of the code, the code of pollutants) - table 2.

Induced relation: POLLUTANTS AND THEIR PARAMETERS (code type of cleaning operation parameters, the code type of pollutant, parameters pollutant) - table 7 .

Induced relation: NAME REAGENTS AND THEIR PARAMETERS (code of cleaning type, code of cleaning method, code of reagent type, name and parameters reagent) - table 10.

\section{Normalization of Database Relation}

Repeated duplication of information except for various anomalies of editing (insertion anomaly, an anomaly updating, and deleting anomaly) lead to lower productivity database. Each data item should be stored in the database only in one copy. It can be achieved through a process of data normalization.

Induced relation CLEANING METHODS AND REACTION TYPES in the first normal form 1NF were 
obtained by taking the normalization method based on subschema database (Figure 2) that is presented in table 2.

Table 2. Methods of Cleaning and Types of Reactions 1NF

\begin{tabular}{|c|c|c|c|c|c|c|c|c|}
\hline $\begin{array}{l}\text { Code of } \\
\text { cleaning } \\
\text { type }\end{array}$ & $\begin{array}{l}\text { Cleaning } \\
\text { method } \\
\text { code }\end{array}$ & $\begin{array}{l}\text { The name of } \\
\text { the cleaning } \\
\text { method }\end{array}$ & $\begin{array}{c}\text { Code of } \\
\text { reaction } \\
\text { type }\end{array}$ & $\begin{array}{l}\text { Type of } \\
\text { reaction }\end{array}$ & $\begin{array}{l}\text { The } \\
\text { constan } \\
\text { t of } \\
\text { reaction }\end{array}$ & $\begin{array}{l}\text { The order } \\
\text { of } \\
\text { chemical } \\
\text { reaction }\end{array}$ & $\begin{array}{c}\text { The code of } \\
\text { operelationnal } \\
\text { parameters }\end{array}$ & $\begin{array}{c}\text { Code of } p \\
\text { ollutants }\end{array}$ \\
\hline 1 & 2 & 3 & 4 & 5 & 6 & 7 & 8 & 9 \\
\hline 01 & M1 & $\begin{array}{c}\text { Reactant } \\
\text { purification }\end{array}$ & 80 & Neutralization & 1 & 1 & A1 & ZI \\
\hline 01 & M1 & $\begin{array}{c}\text { Reactant } \\
\text { purification }\end{array}$ & 81 & $\begin{array}{c}\text { Heavy metal } \\
\text { deposition }\end{array}$ & 4 & 2 & A2 & ZI \\
\hline 01 & M1 & $\begin{array}{c}\text { Reactant } \\
\text { purification }\end{array}$ & 82 & Deactivation & 3 & 1 & A3 & ZI \\
\hline 01 & M1 & $\begin{array}{c}\text { Reactant } \\
\text { purification }\end{array}$ & 83 & Coagulation & 2 & 1 & A5 & ZI \\
\hline .. & $\ldots$ & $\cdots$ & $\ldots$ & $\cdots$ & $\ldots$ & $\ldots$ & $\ldots$ & $\cdots$ \\
\hline
\end{tabular}

The relation of the purification method is written in the third normal form $3 \mathrm{NF}$ in the following way:

Table 3. Cleaning Methods 3NF

\begin{tabular}{|c|c|c|}
\hline $\begin{array}{c}\text { Code of } \\
\text { cleaning type }\end{array}$ & $\begin{array}{c}\text { Cleaning method } \\
\text { code }\end{array}$ & $\begin{array}{c}\text { The name of the cleaning } \\
\text { method }\end{array}$ \\
\hline 1 & 2 & 3 \\
\hline 01 & M1 & Reactant purification \\
\hline 01 & M2 & Flotation \\
\hline 01 & M3 & Ion exchange \\
\hline 01 & M4 & Electrochemical methods \\
\hline$\ldots$ & $\ldots$ & $\ldots$ \\
\hline
\end{tabular}

The relation TYPES OF REACTION firstly should be written in second normal form 2NF:

Table 4. Types of Reaction $2 \mathrm{NF}$

\begin{tabular}{|c|c|c|c|}
\hline $\begin{array}{c}\text { Code of } \\
\text { reaction } \\
\text { type }\end{array}$ & Type of reaction & $\begin{array}{c}\text { Constant of } \\
\text { reaction }\end{array}$ & $\begin{array}{c}\text { Order of } \\
\text { reaction }\end{array}$ \\
\hline 1 & 2 & 3 & 4 \\
\hline 80 & Neutralization & 0,1 & 1 \\
\hline 81 & $\begin{array}{c}\text { Heavy metals } \\
\text { deposition }\end{array}$ & 4 & 2 \\
\hline 82 & Deactivation & 3 & 1 \\
\hline 83 & Coagulation & 6 & 1 \\
\hline$\ldots$ & $\ldots$ & $\ldots$ & $\ldots$ \\
\hline
\end{tabular}

Finally, the relation TYPES OF REACTION can be written in the third normal form 3NF: 
Table 5. Types of Reaction 3NF

\begin{tabular}{|c|c|c|c|c|}
\hline $\begin{array}{c}\text { Code of reactions } \\
\text { type }\end{array}$ & Type of reaction & $\begin{array}{c}\text { Cleaning } \\
\text { type code }\end{array}$ & $\begin{array}{c}\text { Cleaning method } \\
\text { code }\end{array}$ & $\begin{array}{c}\text { Reaction } \\
\text { parameterscode }\end{array}$ \\
\hline 1 & 2 & 3 & 4 & 5 \\
\hline 80 & Neutralization & 01 & 1 & 31 \\
\hline 81 & Heavy metals deposition & 01 & 2 & 32 \\
\hline 82 & Deactivation & 01 & 1 & 33 \\
\hline 83 & Coagulation & 01 & 1 & 34 \\
\hline$\ldots$ & $\ldots$ & $\ldots$ & $\ldots$ & $\ldots$ \\
\hline
\end{tabular}

The relation THE PARAMETERS OF REACTION can be written in third normal form $3 \mathrm{NF}$ as the following:

Table 6. Parameters of Reaction 3NF

\begin{tabular}{|c|c|c|c|c|c|}
\hline $\begin{array}{c}\text { Code of reaction } \\
\text { parameters }\end{array}$ & $\begin{array}{c}\text { Constant of } \\
\text { reaction }\end{array}$ & $\begin{array}{c}\text { Order of } \\
\text { chemical } \\
\text { reaction }\end{array}$ & $\begin{array}{c}\text { Code of } \\
\text { cleaning } \\
\text { type }\end{array}$ & $\begin{array}{c}\text { Code of } \\
\text { cleaning } \\
\text { method }\end{array}$ & $\begin{array}{c}\text { Code of } \\
\text { reactions type }\end{array}$ \\
\hline 1 & 2 & 3 & 4 & 5 & 6 \\
\hline 21 & 0,1 & 1 & 01 & $\mathrm{M} 1$ & 80 \\
\hline 22 & 4 & 2 & 01 & $\mathrm{M} 1$ & 81 \\
\hline 23 & 3 & 1 & 01 & $\mathrm{M} 1$ & 82 \\
\hline 24 & 6 & 1 & 01 & $\mathrm{M} 1$ & 83 \\
\hline$\ldots$ & $\ldots$ & $\ldots$ & $\ldots$ & $\ldots$ & $\ldots$ \\
\hline
\end{tabular}

Induced relation POLLUTANTS AND THEIR PARAMETRES in the first normal form 1NF was obtained by using normalization with the help of subschema database (Figure 2) and was represented in table 7:

Table 7. Pollutants and Their Parameters 1NF

\begin{tabular}{|c|c|c|c|c|c|c|c|}
\hline $\begin{array}{c}\text { Code of } \\
\text { cleaningt } \\
\text { ype }\end{array}$ & $\begin{array}{c}\text { Code of } \\
\text { operelationnal } \\
\text { parameters }\end{array}$ & $\begin{array}{c}\text { Code of } \\
\text { type of } \\
\text { pollutant }\end{array}$ & $\begin{array}{c}\text { The name } \\
\text { of pollutant }\end{array}$ & $\begin{array}{c}\text { Molar } \\
\text { mass }\end{array}$ & $\begin{array}{c}\text { Dissociation } \\
\text { constant }\end{array}$ & $\begin{array}{c}\text { The } \\
\text { density of } \\
\text { the } \\
\text { aqueous } \\
\text { solution }\end{array}$ \\
\hline 1 & 2 & 3 & 4 & 5 & 6 & 7 & 9 \\
\hline 01 & AI & 100 & $\begin{array}{c}\text { Sulfuric } \\
\text { acid }\end{array}$ & 98 & $1 * 10^{3}$ & 5 & 1.2 \\
\hline 01 & AI & 100 & $\begin{array}{c}\text { Sulfuric } \\
\text { acid }\end{array}$ & 98 & $1 * 10^{3}$ & 3 & 1.15 \\
\hline 01 & AI & 101 & $\begin{array}{c}\text { Sulfuric } \\
\text { acid }\end{array}$ & 98 & $1 * 10^{3}$ & 2 & 1.11 \\
\hline 01 & AI & 101 & Acetic acid & 60 & $1,75^{*} 10^{-5}$ & 5 & $\ldots$ \\
\hline$\ldots$ & $\ldots$ & $\ldots$ & $\ldots$ & $\ldots$ & $\ldots$ & $\ldots$ & $\ldots$ \\
\hline 01 & AI & 110 & $\begin{array}{c}\text { Sulfuric } \\
\text { acidic iron }\end{array}$ & 152 & $-\ldots$ & $\ldots$ \\
\hline
\end{tabular}

As shown in table 7, the relation of pollutants in third normal form 3NF can be written as the following: 
Table 8. Contaminants 3NF

\begin{tabular}{|c|c|c|c|}
\hline $\begin{array}{c}\text { Code of cleaning } \\
\text { type }\end{array}$ & $\begin{array}{c}\text { Code of operelationnal } \\
\text { parameters }\end{array}$ & $\begin{array}{c}\text { Code of type of } \\
\text { pollutant }\end{array}$ & The name of pollutant \\
\hline 1 & 2 & 3 & 4 \\
\hline 01 & AI & 100 & Sulfuric acid \\
\hline 01 & AI & 101 & Acetic acid \\
\hline$\ldots$ & $\ldots$ & $\ldots$ & Sulfate iron \\
\hline 01 & AI & 120 & $\ldots$ \\
\hline$\ldots$ & $\ldots$ & $\ldots$ & $\ldots$ \\
\hline
\end{tabular}

The relation PARAMETERS OF POLLUTANTS are presented in the third normal form 3NF:

Table 9. Parameters of Pollutants 3NF

\begin{tabular}{|c|c|c|c|c|c|c|}
\hline $\begin{array}{c}\text { Code of } \\
\text { pollutant } \\
\text { parameters }\end{array}$ & $\begin{array}{c}\text { Molar } \\
\text { mass }\end{array}$ & $\begin{array}{c}\text { Dissociation } \\
\text { constant }\end{array}$ & $\begin{array}{c}\text { Initial } \\
\text { concentrelationn }\end{array}$ & $\begin{array}{c}\text { Code of } \\
\text { cleaning } \\
\text { type }\end{array}$ & $\begin{array}{c}\text { Code of } \\
\text { operelationnal } \\
\text { parameters }\end{array}$ & $\begin{array}{c}\text { Code of type } \\
\text { of pollutant }\end{array}$ \\
\hline 1 & 2 & 3 & 4 & 5 & 6 & 7 \\
\hline 130 & 98 & $1 * 10^{3}$ & 5 & 01 & AI & 100 \\
\hline 130 & 98 & $1 * 10^{3}$ & 3 & 01 & AI & 100 \\
\hline 131 & 98 & $1 * 10^{3}$ & 2 & 01 & AI & 101 \\
\hline 132 & 60 & $1,75^{*} 10^{-5}$ & 5 & 01 & AI & 102 \\
\hline$\ldots$ & $\ldots$ & $\ldots$ & $\ldots$ & $\ldots$ & $\ldots$ & $\ldots$ \\
\hline 140 & 152 & - & 10 & 01 & AI & 110 \\
\hline$\ldots$ & $\ldots$ & $\ldots$ & $\ldots$ & $\ldots$ & $\ldots$ & $\ldots$ \\
\hline
\end{tabular}

Induced relation of reagents and their parameters in first normal form $1 \mathrm{NF}$ was obtained by using normalization with the help of subschema database (Figure 2) and is represented in table 10.

Table 10. Name Reagents and Their Parameters 1NF

\begin{tabular}{|c|c|c|c|c|c|c|}
\hline $\begin{array}{c}\text { Code of } \\
\text { cleaning type }\end{array}$ & $\begin{array}{c}\text { Code of } \\
\text { cleaning } \\
\text { method }\end{array}$ & $\begin{array}{c}\text { Code of } \\
\text { reagent type }\end{array}$ & $\begin{array}{c}\text { Name of } \\
\text { reagent }\end{array}$ & $\begin{array}{c}\text { Molar } \\
\text { mass }\end{array}$ & Density & $\begin{array}{c}\text { Concentrelationn } \\
\text { \% }\end{array}$ \\
\hline 1 & 2 & 3 & 4 & 5 & 6 & 7 \\
\hline 01 & M1 & 200 & $\begin{array}{c}\text { Sodium } \\
\text { hydroxide }\end{array}$ & 40 & 1.2 & 4 \\
\hline 01 & M1 & 201 & Limes lurry & 37 & - & 5 \\
\hline$\ldots$ & $\ldots$ & $\ldots$ & $\ldots$ & $\ldots$ & $\ldots$ & $\ldots$ \\
\hline
\end{tabular}

As it is shown in table 11 the relation reagents in third normal form $3 \mathrm{NF}$ can be written as the following:

Table 11. Reagents 3NF

\begin{tabular}{|c|c|c|c|c|}
\hline $\begin{array}{c}\text { Code of reagent } \\
\text { type }\end{array}$ & Name of reagent & $\begin{array}{c}\text { Code of cleaning } \\
\text { type }\end{array}$ & $\begin{array}{c}\text { Code of cleaning } \\
\text { method }\end{array}$ & $\begin{array}{c}\text { Code of reagent } \\
\text { parameters }\end{array}$ \\
\hline 1 & 2 & 3 & 4 & 5 \\
\hline 200 & Sodium hydroxide & 01 & $\mathrm{M} 1$ & 300 \\
\hline 201 & Limes lurry & 01 & $\mathrm{M} 1$ & 301 \\
\hline$\ldots$ & $\ldots$ & $\ldots$ & $\ldots$ & $\ldots$ \\
\hline
\end{tabular}


The relation PARAMETERS OF REAGENTS are shown in third normal form 3NF.

Table 12. Parameters of Reagents 3NF

\begin{tabular}{|c|c|c|c|c|}
\hline $\begin{array}{c}\text { Code of reagent } \\
\text { parameters }\end{array}$ & $\begin{array}{c}\text { Molar } \\
\text { mass }\end{array}$ & Density & Concentrelationn, \% & $\begin{array}{c}\text { Code of } \\
\text { reagent type }\end{array}$ \\
\hline 1 & 2 & 3 & 4 & 5 \\
\hline 300 & 40 & 1.2 & 4 & 200 \\
\hline 301 & 37 & - & 5 & 201 \\
\hline$\ldots$ & $\ldots$ & $\ldots$ & $\ldots$ & $\ldots$ \\
\hline
\end{tabular}

As the result of normalization, the relational model database was obtained and was presented in the form of the relation-tables union. Relation-tables satisfy the following requirements: lack of repeating groups (each table element represents one element of data, all columns are homogeneous, the lack of the same lines). In the process of operation with the relation-table its lines and columns can be revised in any order regardless of the information content.

Each tuple has key-identifier, (e. g. code of cleaning type, code of cleaning method, code of reagent type) presented in table 10. Key relation can contain in addition to primary keys also secondary keys by which tuples of this relation are uniquely identified.

One advantage of relational data structure is a simple reorganization of the database. Reorganization of the database is a concept that has two interpretations. In a broad sense, it is any change in the organization of the database, including restructuring. In a narrow sense, it is only changes at the physical level without making any changes at the logical level. We consider the term "reorganization" in its narrow sense.

The need in reorganization of the database relates to the necessity to improve its functional characteristics. The database is often reorganized to compress and release its memory. So, excluded from the database records are first noted to be removed. Selected entries are not always physically destroyed; they can be placed in a database for a while. For example, the cost of raw materials over the past shift and the past day and the use of basic technological equipment for the past day are remained at the company for the formation of accounting and statistical reports and for other purposes. However, this information is impractical to keep in the active database (in the collection of data) and therefore the reorganization is carried out and the records which were marked above for removal are rewritten in archive files.

Most of the known database management systems have command of record and the physical destruction of records, but they don't have any programs for consolidation and reorganization of the database, so that is the reason for developing such programs separately. Interval of reorganization is defined by administrator of the database. The frequency of reorganization depends on the intensity and characteristics of modifications, intensity of usage of database files and others.

Restructuring is a process of changing the database files in the logical structure. These changes include changes in the types, formats and names of individual fields, the emergence of new fields, exclusion of some fields from the structure of the file and its realignment. The main objective reason for restructuring is that any subject area reflected in the database may experience certain changes thus resulting in the need to restructure the database. Another reason is the emergence of new user information needs not planned in the design of database.

Restructuring of database for most database management systems needs full or partial restart, due to costly computer time and requires a large and serious work. That is caused by the amendment of the relevant applications that work with the liable to restructuring files. 


\section{Selection of Database Management System}

Implementation of logical data model is primarily associated with the choice of a database management system for managing tasks in an automated process control system for typical wastewater treatment processes. This task is not easy as for its solution many factors should be evaluated. It is necessary to predict both the prospects of development of the company, for which the choice is made in terms of expanding the functions and tasks as well as to learn the software tools market. There are two approaches to assess the database management system. The first approach involves the choice of database management systems in terms of a user perspective and the second is purely based on technical and is associated with system productivity.

Given these two points of view, the choice of database management systems can be made based on their analysis on the following parameters.

A) General characteristics: these include the type of logical database model, the type of computer, operating environment, database management systems quantitative restrictions (maximum size of the database, the maximum size of the table, the maximum recording size, the maximum field size, maximum entries in the table, maximum fields in the record, maximum indices in the table); manufacturer, random access memory, system type (open, closed); language of the system (own language, the $\mathrm{C}++$ programming language", etc.); versions number, that indicates the demand of the system and attempts of manufacturer to improve the system .

B) Support Tools of software applications [14], includes:

- availability of query language based on SQL or other languages;

- availability of embedded programming languages.

C) Means of support networking. The possibility of database management systems to work in the network for controlling the process of purification was determined as the following:

- the ability to work in a local network;

- availability of automated tools of monitoring the consistency and data integrity of network in the collective use of data; particularly at the beginning of the query it makes copies of all files involved in its implementation. So, you can run queries of any complexity, because all proofs made by other users in the database files during the query processing do not affect the result;

- mechanism for tracking the time of a transaction. This mechanism is needed to prevent the system hang during the process of the collective data usage. If the limit of allowable time for the transaction is expired, it is overridden and the database returns to its original state.

At the present time, there is no generally accepted analytical method of database management system choice. Therefore, experts in data management field for the solution of this task use such methods:

- methods of simulation;

- experimental studies with using full scale tests;

- heuristic method having such points in the comparative evaluation of characteristics as "yes-no", "present - absent," "good - satisfactory - bad."

While using simulation modeling techniques there can appear some additional problems in evaluation of database simulation model accuracy. Obtaining comparative characteristics of database management system with the help of full scale test is associated with significant labor costs. Therefore, the choice of database management system for maintaining a database for automated process control of typical wastewater treatment processes is based on expert estimates (table 13). 
Table 13. Criteria for Selection of DBMS of ACS of Typical Wastewater Treatment Processes

\begin{tabular}{|c|c|c|c|}
\hline Indicator & \multicolumn{2}{|c|}{ Database management system PostgreSQL } & Points \\
\hline The data structure & \multicolumn{2}{|c|}{ Relational } & «yes» \\
\hline Operating System & \multicolumn{2}{|c|}{ Unix, Windows } & «yes» \\
\hline Type of system & \multicolumn{2}{|c|}{ Opened } & «yes» \\
\hline \multirow[t]{7}{*}{ Settings of system } & Maximum size of the database & No restrictions & \multirow{7}{*}{ «good» } \\
\hline & Maximum size of the table & $32 \mathrm{~TB}$ & \\
\hline & Maximum size of the record & $1.6 \mathrm{~TB}$ & \\
\hline & Maximum sizes of the field & $1 \mathrm{~GB}$ & \\
\hline & Maximum records in the table & No restrictions & \\
\hline & Maximum fields in the record & $\begin{array}{l}250-1600 \text {, depending on the types } \\
\text { of fields }\end{array}$ & \\
\hline & Maximum indexes in the table & No restric-tions & \\
\hline $\begin{array}{l}\text { The ability to support the modules } \\
\text { written in other programming } \\
\text { languages }\end{array}$ & \multicolumn{2}{|c|}{$\begin{array}{l}\text { The ability to support } \mathrm{C} \text { and } \mathrm{C}++ \text { compatible modules; embedded } \\
\text { system programming language PL / pgSQL, PL / Java, etc. }\end{array}$} & «yes» \\
\hline $\begin{array}{l}\text { The presence of a query language } \\
\text { based on SQL }\end{array}$ & \multicolumn{2}{|l|}{ Exist } & «yes» \\
\hline $\begin{array}{l}\text { The presence of mechanisms for } \\
\text { transactions and replication }\end{array}$ & \multicolumn{2}{|c|}{ Highly efficient transaction and replication mechanisms. } & «good» \\
\hline
\end{tabular}

Figure 3 shows the architecture of the database of automated control system of typical wastewater treatment processes.

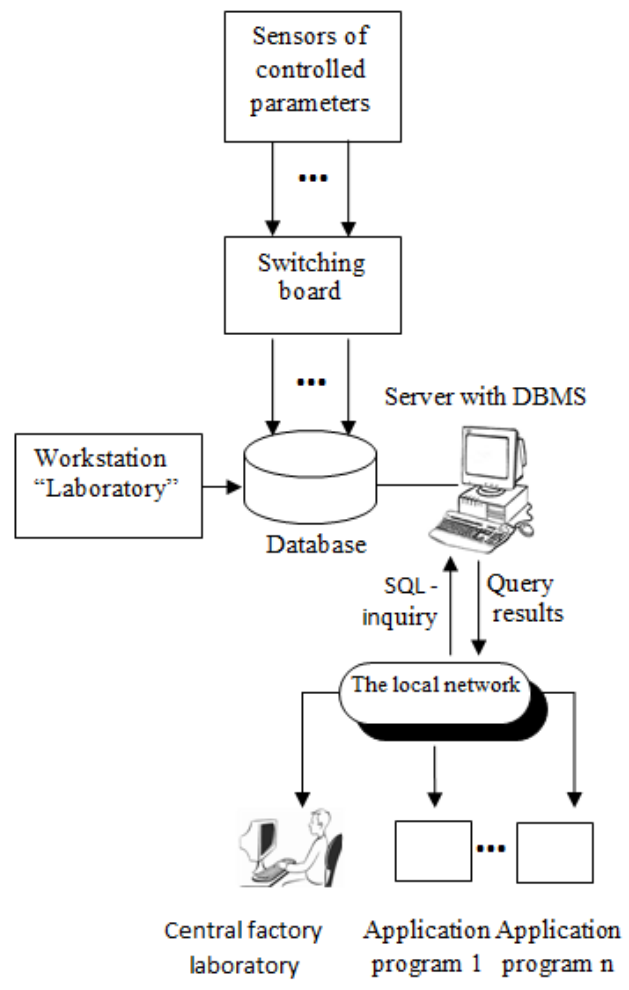

Fig.3. Client-Server Database Architecture 
The choice for database management system is based on indicators represented in table 14 and it is another result of this work. For the maintenance of the database that is based on the criteria listed above the system of relational database management RostgreSQL was chosen.

\section{Summary}

A subschema database for the automated control system of typical wastewater treatment processes was proposed. On its basis, by using normalization relational data, structure was obtained and has substantial advantages over the hierarchical and mesh data structures. They are the following:

- relational (tabular) data structure for a person is the most illustrative and most understood;

- the ability to use finished relational algebra (a language of Codd algebra);

- easy reorganization of database.

The attributes relation to composition of the database is the result of normalization, and meets such requirements that there is no undesirables the functional dependences between attributes; the attributes grouping ensures minimal duplication of data, its processing and renews without complications or anomalies. In this case, there are the following conditions: a) all attributes in relation are inseparable (atomic); b) the relation doesn't have any duplicate rows or columns; c) all attributes have unique names. That means that informational objects of the subschema are relational ratios, and it is not necessary to redesign them after the stage of normalization.

As noted, the relational database is based on ready-description language, relational algebra, and data processing, which is being a significant advantage of this model. Data processing is easily standardized, because the search result also comes in the form of relation. Requests in the relation database are formed on the language based on algebra relations. One or more based on request tuples can be found, each of which also may consist of one or more domains.

Another advantage of the relation database is a simple introduction of new data, but only if ID-key introduced tuple differs from the keys of the other tuple relations. When you remove the tuple all tuples in other relations should be deleted, if they contain the notion of key tuple, that is removed. These minor restrictions of removal operations and updating are disadvantages of relational database.

Presented approaches and criteria allowed us to make the choice of database management system and it will help to get to its physical realization. Transaction of database will provide the database management system Postgre SQL, that incorporates the system of embedded programming languages $(\mathrm{C}++, \mathrm{C}$, PL / Java, and others), the query language SQL will develop interface with application software of the automated control system.

Client-server architecture of database of ACS of typical wastewater treatment processes will not only help to store data on a central computer but also to perform basic operations and data processing. The specificity of this architecture is the use of query language SQL. The user will not get files, but only the data that he chose.

The use of the database allows managing the technical process of wastewater treatment more efficient and it helps to reduce the ingress of contaminants into the environment. Further development of the database will be linked to the introduction of workstation "Laboratory" for receiving and displaying of pollution rapid analysis by wastewater, and the introduction of information on the most common methods of wastewater treatment.

In addition, with the growing amount of data on static and dynamic characteristics of the typical cleaning processes information of the third sub schema lower level of the database will be recorded as chapters of factual database. New prospective Automated Information System of automated control system of typical wastewater treatment processes will be commissioned in the nearest future. 


\section{References}

[1] R. Connor, The United Nations world water development report 2015: water for a sustainable world. UNESCO Publishing, 2015. -T. 1. -125 pages.

[2] E. Illarionova I. Syirovatskiy, "Analysis of sewage”. Minzdrav RF. - Irkutsk, 2013. - 53 pages.

[3] V. Plehov, V. Dyachenko, I. Dyachenko, "Automation of the processes of biological purification of wastewaters of oil industry enterprises." - Perm.: Bulletin of the Perm National Research Polytechnic Institute. Chemical technology and biotechnology. №14, 2012. pp. 22-33.

[4] D. Ignatev, E. Mitin, "Improvement of the current technological process of sewage treatment of galvanic production from heavy metal impurities and waste generation." Privolzhsky scientific herald. Chemical sciences. №12-1 (52). 2015. pp. 5-9.

[5] O. Kopyilevich, Development of the upper level of the automated process control system for sewage treatment of refining production // Young people and science: A collection of materials of the VIII AllRussian scientific and technical conference of students, graduate students and young scientists dedicated to the 155th anniversary of K. Tsiolkovsky [Electronic resource]. - Krasnoyarsk: Siberian Federal University, 2012. - Access mode: http://conf.sfu-kras.ru/sites/mn2012/section03.html

[6] A. Zhuchenko, R. Osipa and L. Osipa, "Optimization tasks, which are solved in the integrated automated control system of water saving processes.", Bulletin of the National Technical University of Ukraine "KPI named after I. Sikorsky", ser. "Chemical Engineering, Ecology and Resource Saving ", 2016. vol. 15, no 1, pp. 108-110.

[7] Ju. Embulaev, M. Volkovoj, N. Matushkin, "Automated process control system for wastewater treatment", System integration, -1999. no 2, pp. 46-51, available at: http://www.cta.ru/cms/f/366618.pdf (Accessed February 08, 2017).

[8] K. Ivanov, A. Efremov, I. Vaschenko, "Database design. The role of the process in the creation of an information system.” -Moscow: Young Scientist, - 2016. №18. pp. 40-42.

[9] A. Zhuchenko, L. Yaroschuk, "Fundamentals of Database Design". - Kyiv: «Agrar Media Group», 2017. - 158 pages.

[10] J. Martin, "Computer data-base organization." - New Jersey: Prentice-Hall, Inc., Englewood Cliffs, 1977. - 562 pages.

[11] A. Zhuchenko, R. Osipa. "Information retrieval on the World Wide Web". - Kyiv: «Agrar Media Group», 2016. - 125 pages.

[12] Vishal Jain, Dr. Mayank Singh, "Ontology Based Information Retrieval in Semantic Web: A Survey", International Journal of Information Technology and Computer Science (IJITCS), Hongkong, Vol. 5, No. 10, September 2013, pp. 62-69.

[13] Narinder K. Seera, Vishal Jain Perspective of Database Services for Managing Large-Scale Data on the Cloud: A Comparative Study. International Journal of Modern Education and Computer Science (IJMECS), Vol.7, No. 6, June 2015, pp. 50-58.

[14] Wang Guan, Wang Xiaolu, Database Design of a General Data Analysis System of Commodity Sales Information, International Journal of Engineering and Manufacturing (IJEM), 2011, No.2, pp. 21-27. 


\section{Author's Profiles}

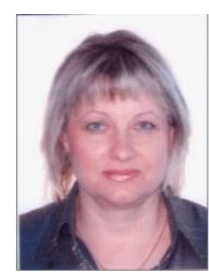

Assis. Prof. Liudmyla V. Osipa is working as assistant professor of Electronic and Computer Engineering at the National Transport University, Kyiv, Ukraine. Her research includes automatic control system, database, machine translation, modern education, computer science. Author 27 research papers in reputed journals and conferences. She is reachable at 1_osipa@ukr.net.

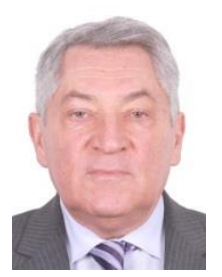

Prof. Anatolii I. Zhuchenko is working as Professor \& Head of the Automation of Chemical Production Department at National Technical University of Ukraine "Igor Sikorsky Kyiv Polytechnic Institute". His research includes automatic control system, control of complex chemical-technological systems database, mathematical modeling and optimal process control. Author of more than 200 research papers in reputed journals and conferences. Contact e-mail: zhaniv@ukr.net.

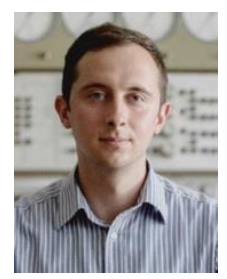

Evgeniy S. Cheropkin is working as Assistant at the Automation of Chemical Production Department at National Technical University of Ukraine "Igor Sikorsky Kyiv Polytechnic Institute". His research includes automatic control system, technology of artificial intelligence, machine learning, using web technology for creation of automatic control systems. Author 34 research papers in reputed journals and conferences. Contact e-mail: e.cheropkin@kpi.ua.

\section{REVIEWERS:}

Yurii Zaychenko, Doctor of Technical Sciences, professor, Institute of Applied Systems Analysis, National Technical University of Ukraine "Igor Sikorsky Kyiv Polytechnic Institute", Prospect Pobedy, 37, Kyiv, Ukraine, 03056

E-mail: zaychenkoyuri@ukr.net

Kyiv, Ukraine

Victor Danchuk, Doctor of Fisic-mathimatical Sciences, chief of the information technology department, professor,

National Transport University of Ukraine, str. Suvorova 3, Kyiv, Ukraine, 01010

E-mail:vdanchuk@ukr.net

Kyiv, Ukraine. 
Victor Lyaskovskii, Ph. D., Director International education center of the informatics technology, National Transport University,

str. Suvorova 3, Kyiv, Ukraine, 01010

E-mail: lvp@ntu.edu.ua

Kyiv, Ukraine.

How to cite this paper: Anatolii I. Zhuchenko, Liudmyla V. Osipa, Evgeniy S. Cheropkin,"Design Database for an Automated Control System of Typical Wastewater Treatment Processes", International Journal of Engineering and Manufacturing(IJEM), Vol.7, No.4, pp.36-50, 2017.DOI: 10.5815/ijem.2017.04.04 